\title{
Pooled Energy Budget and Human Life History
}

\section{Citation}

Reiches, Meredith W., Peter T. Ellison, Susan F. Lipson, Katherine C. Sharrock, Eliza Gardiner, Laura G. Duncan. 2009. Pooled Energy Budget and Human Life History. American Journal of Human Biology (forthcoming).

\section{Published Version}

http://www3.interscience.wiley.com/journal/37873/home

\section{Permanent link}

http://nrs.harvard.edu/urn-3:HUL.InstRepos:2757545

\section{Terms of Use}

This article was downloaded from Harvard University's DASH repository, and is made available under the terms and conditions applicable to Open Access Policy Articles, as set forth at http:// nrs.harvard.edu/urn-3:HUL.InstRepos:dash.current.terms-of-use\#OAP

\section{Share Your Story}

The Harvard community has made this article openly available.

Please share how this access benefits you. Submit a story.

Accessibility 


\section{Pooled Energy Budget and Human Life History}

Meredith W. Reiches ${ }^{1 *}$, Peter T. Ellison ${ }^{1}$, Susan F. Lipson ${ }^{1}$, Katherine C. Sharrock ${ }^{1}$, Eliza Gardiner $^{1}$, and Laura G. Duncan ${ }^{2}$

${ }^{1}$ Department of Anthropology, Harvard University, Cambridge, MA 02138

${ }^{2}$ Gallatin School of Individualized Study, New York University, New York, NY 10003

* Corresponding author

Meredith Reiches

Department of Anthropology

Harvard University

11 Divinity Ave.

Cambridge, MA 02138

Phone: (617) 495-1679

Fax: (617) 496-8041

mreiches@,fas.harvard.edu

Keywords: life history theory, reproductive ecology, cooperative breeding 


\begin{abstract}
Human life history contains a series of paradoxes not easily explained by classical life history theory. While overall reproductive output is higher than in related primates, juvenile growth is slower and age-specific reproductive rates decline faster with age. A simple energetic model would predict that growth and reproductive rates should be positively correlated and that reproductive effort should not decelerate with age. The pattern of negative correlations in humans suggests the presence of trade-offs among peak reproductive rate, childhood growth, and reproductive rate at older ages. To address this puzzle, we propose a synthesis of reproductive ecology and behavioral ecology focused on intra- and inter-somatic energy transfers. This integration includes three concepts: the mother as final common pathway through which energy must pass to result in offspring; a distinction between direct and indirect reproductive effort, proposing the latter as a novel net energy allocation category relative to growth and direct reproductive effort; and a pooled energy budget representing the energetic contributions and withdrawals of all members of a breeding community. Individuals at all reproductive life stages are considered in light of their contributions to the pooled energy budget.
\end{abstract}




\section{Introduction}

Since its inception, life history theory has been applied successfully to explain variation in growth, reproduction, and senescence strategies at the individual and species level. "Life history" refers to the way that organisms allocate time and energy among growth, maintenance, and reproduction (Gadgil and Bossert 1970). There are inherent tradeoffs among these categories: energy allocated to growth cannot be used simultaneously for reproduction or for maintenance. Time constraints introduce opportunity costs as well. Human life history, however, particularly female human life history, poses challenges to the classical model.

Age at puberty in humans is later than would be expected for a primate of our size (Bogin 1999b). Late age at reproductive maturation appears to be a consequence of protracted juvenile growth; humans grow more slowly relative to their body size than do chimps (Bogin 1999b). Greater brain growth and increased brain maintenance costs may contribute to slower somatic growth rates, though it is not clear that they make a net difference. Several researchers have argued that, while the costs of brain growth and maintenance have increased in humans, the costs of other expensive tissues, including gut and muscle mass, have decreased, the two more or less offsetting each other (Aiello and Wheeler 1995; Gurven and Walker 2006; Janson and van Schaik 1993; Leonard and others 2003; Wrangham and others 1999). On a kilogram basis, basal metabolic rate does not differ significantly between immature chimpanzees and humans (Froehle and Schoeninger 2006), suggesting that this measure of individual metabolic budget has not changed since the last common ancestor of these two species. Rather, it appears that humans allocate less energy to growth during the juvenile period than would be expected of a hominoid of our size.

Although the rate of energy allocation to juvenile growth is lower in humans than in other hominoids, the rate of energy allocation to reproduction after maturity is much greater. Interbirth intervals are shorter on average and periods of dependency of individual offspring are longer. Many authors have noted this acceleration of human reproductive effort relative to that of other hominoids and, presumably, relative to the last common ancestor of chimpanzees and humans.

Each of these departures in pattern from the hominoid norm - lower energy allocation to growth and greater energy allocation to reproduction - is notable in itself and requires explanation. But the combination of the two is even more remarkable. Charnov and Berrigan (1993) note that, across mammalian taxa, energy allocation to growth and reproduction are comparable in rate, representing alternative allocation of available metabolic energy net of maintenance requirements. Such a model of residual metabolic productivity predicts a positive correlation between juvenile growth rate and peak adult reproductive rate. In keeping with this pattern, they argue, primates tend to have less net metabolic energy available per mass and hence tend to grow more slowly and reproduce more slowly than comparably sized mammals from other orders. Within taxa, large species tend to have less net metabolic energy per mass than smaller species, and hence tend to both grow and reproduce more slowly. Humans, on the other hand, present a negative correlation: they tend to grow more slowly than expected, even for a hominoid of equivalent size, while reproducing more quickly. 
Within mature females, energy allocation to reproduction also follows unexpected patterns. A standard prediction of life history theory is that allocation to reproduction should increase at the expense of allocation to maintenance as reproductive value declines with advancing age. The actual production of offspring may not increase markedly if reproductive efficiency declines due to somatic senescence. However, compared to chimpanzees, and thus presumably compared to the last common ancestor of chimpanzees and humans, human fecundity begins to decline a decade in advance of menopause without evidence of somatic compromise.

Thus human life histories have evolved a very unusual pattern of energy allocation that presents several paradoxes: Where does the energy unused in juvenile growth go? Where does the additional energy allocated to reproduction in adulthood come from? Where does it go as a woman ages? It is seemingly impossible for a standard model of energy allocation based on fractionation of individual metabolic productivity to encompass these contradictions, since it would require net energy to decrease, then increase, then decrease, or for maintenance requirements to follow the opposite pattern of rise and fall across the lifespan.

A number of theoretical approaches to the evolution of paradoxical human life history characteristics have been advanced by others, and our approach has significant areas of overlap with most of them. Most theories of human life history, however, do not directly confront these "thermodynamic" paradoxes. Previous approaches envision human groups cooperating at various levels in production, consumption, and domestic activities. Several emphasize special degrees of cooperation between females in the tasks of childcare. They underscore contributions of siblings and grandparents to both food acquisition and domestic activities (Hawkes and others 1998; Hrdy 2007). The role of adult males and the function of pair bonds figures in many accounts, either as a source of provisioning and domestic assistance or as a source of protection from other males (Hill and Kaplan 1999; Lancaster and Lancaster 1983; Rodseth and others 1991). Almost all interpret extended periods of immaturity in humans (relative to other hominoids) as closely related to knowledge and skill acquisition, and often directly to brain growth and maturation as well (Bogin 1999a; Kaplan and others 2000).

We distinguish our approaches from these others by virtue of our explicit focus on energy, the patterns of energy allocation within and between individuals, and the degree to which these patterns support reproduction. Unlike other approaches, we do not concern ourselves with augmentations in knowledge or skill. We are not focused on the benefits of allomothers or fathers to offspring survival per se. Rather, we concentrate on energy allocation that has the ultimate effect of increasing the flow of energy to direct reproduction. By "following the calories" we feel that a number of the principal enigmas of human life histories can be largely resolved, in some cases leading to novel interpretation of the selective forces involved and the functionality of particular attributes, in other cases merely limiting the need for additional theoretical scaffolding. We suggest that it is not only possible to resolve these issues in strict, energy allocation terms, but that doing so generates a satisfying synthesis of empirical and theoretical work from the domains of reproductive ecology, behavioral ecology, and life history theory.

\section{Reproductive ecology and intra-somatic energy transfers}


It has been demonstrated that humans respond to their environment with adaptive forms of energy storage and mobilization in ways that increase reproductive success (Ellison 1994). Much of this work comes from the field of reproductive ecology, the study of the energetics of reproduction in relation to the environment (Ellison 2003). The costs of reproduction for human females include the production of a mature follicle, preparation of the endometrium for implantation, gestation, and lactation. Some of the costs of late gestation and lactation are anticipated in the first trimester of pregnancy, when maternal adipose stores, especially in the gluteofemoral and mammary regions, increase. These fat depots are preferentially mobilized in the third trimester to support fetal adipose accumulation and brain growth, and after birth to fund lactation (Freinkel 1980; Homko and others 1999; Lassek and Gaulin 2006), which represents a higher per diem caloric expenditure than gestation (Dufour and Sauther 2002).

The minimum costs of gestation and lactation in females are both fixed; it is impossible to produce viable offspring with less than a minimally sufficient investment in each. Thus it is adaptive to commit to these expenditures only when prospects for success are reasonable and only to a degree that optimizes lifetime reproductive success. Human female physiology has evolved to use current energetic parameters to modulate energetic investment in reproductive effort. This is a predictive strategy: given the seasonal but irregular nature of environments of evolutionary relevance to humans, a female's current energetic condition was the best estimate of future energy availability (deMenocal 2004; Ellison 1994), since it may not have been possible to time lactation, the period of highest per diem caloric cost, with a suitably long season of plentiful resources. It follows that conception is likely to occur when females are in positive energy balance, i.e. gaining weight, and less so when they are either losing weight or maintaining a steady weight but committed to expending large amounts of energy. Evidence from several studies (Jasienska and others 2006; Lipson and Ellison 1996; Venners and others 2006) shows that positive energy balance and lower energy flux lead to higher ovarian steroid levels, and higher ovarian steroid levels correlate with greater likelihood of conception.

Facultative response of reproductive function to energy balance and flux is by no means unique to humans. While less is known about gorillas, recent research indicates that energy availability and probability of conception are linked in chimpanzees and orangutans. In chimpanzees, high energy availability is associated with higher levels of ovarian steroid hormone metabolites in urine, larger sexual swellings, and greater likelihood of conception (Emery Thompson 2005; Knott 2001). In orangutans, whose southeast Asian environment is characterized by alternating, extreme periods of fruit availability (called "masting") and long periods without fruit, conceptions tend to coincide with fruit tree masting (Wich and others 2006). It is not known whether chimpanzees, orangutans, and humans vary significantly in their ovarian responsiveness to energy availability.

One final aspect of the ability to coordinate conception with periods of high energy availability concerns the timing of the return to fecundity after giving birth. This window of lactational amenorrhea sets the lower limit on inter-birth intervals. As an infant grows, it begins to incorporate supplemental foods into its diet, usually starting around six months, and becomes less dependent on milk (Skinner and others 1997). Concurrently, mothers may improve in energetic condition with increasing time after giving birth (Ellison 1995). Studies in well-nourished women who nurse on demand 
indicate that the mother's energetic condition and the infant's consumption of supplemental foods are the best predictors of the post-partum resumption of ovarian activity (Ellison and Valeggia 2003; Howie and McNeilly 1982; McNeilly 2001a; McNeilly 2001b; Valeggia and Ellison 2004). This contrasts with the fact that the length of infant dependency is the key determinant of inter-birth interval in great apes, particularly in chimpanzees. Human females in environments of high energy availability and low energy expenditure will return to fecundity more quickly than women who consume fewer calories and/or expend more (Ellison 1995).

In addition to the ability to modulate reproductive investment relative to energy availability, humans show adaptive patterns of energy storage and mobilization via adipose tissue. Although the propensity to store energy in the form of fat leads to adverse health outcomes in societies with overabundant caloric availability and low energy expenditure, this capacity would have been adaptive under conditions of energetic scarcity and unpredictability. Some facets of human fat storage ability, however, remain remarkably strategic and physiologically revealing. During the third trimester of gestation, the fetus lays down fat stores at a particularly high rate. (For an extensive review of infant adiposity, see (Kuzawa 1998).) Third trimester fetal fat accumulation often involves mobilization of maternal adipose reserves established early in pregnancy (Herrera 2002). Birth weight and neonatal adiposity in turn are important predictors of infant survival (McCormick 1985; Verloove-Vanhorick and others 1986). The pattern of first trimester maternal adipose deposition and third trimester fetal adipose mobilization is crucial in gestational physiology to the point that malnourished mothers down-regulate their own basal metabolic rates in the first trimester to support the establishment of these fat stores (Poppitt and others 1993; Prentice and others 1993; Prentice and Goldberg 2000; Prentice and others 1996; Prentice and others 1995). A similar increase in infant adipose stores provides a buffer for the weaning period (Kuzawa 1998). The ability to accumulate and store energy during periods of surplus and to mobilize it during periods of deficit is thus crucial to successful human reproduction as well as to survival.

The accelerated somatic growth and body composition changes of puberty likewise represent an adaptive, albeit sexually dimorphic, use of energy. Both male and female humans undergo a more marked linear growth spurt in adolescence than do chimpanzees (Bogin 1999a). Under the influence of estrogen produced by the ovaries, females develop gluteofemoral and mammary adipose depots, rich in omega-3 docosahexaenoic acid, which are preferentially mobilized during late stage pregnancy and lactation (Del Prado and others 2000; Demmelmair and others 1998; Fidler and others 2000; Fredriks and others 2005; Hachey and others 1987; Hammer and others 1991). Under the influence of testosterone, males selectively allocate energy to the production and maintenance of muscle (Bribiescas 2001). In the transition to mature reproductive function, therefore, we see further evidence of reproductively adaptive intrasomatic allocation of energy.

\section{Behavioral ecology and inter-somatic energy transfers}

While a great deal is known about how individuals allocate and transfer energy within their bodies, it is important to consider a crucial feature of human society: members of all known cultures transfer food between bodies, from person to person 
(Isaac 1978; Kaplan and Gurven 2005; Kaplan and Hill 1985). This pattern is hardly unique in the animal kingdom, though it is more common in birds, insects, and social carnivorous mammals than it is in primates (Kaplan and Gurven 2005). In addition, many mammals, including some primates, are considered cooperative breeders. The behavioral ecology subfield of cooperative breeding examines how individuals in a community contribute to the care and sustenance of offspring that are not their own. Alloparenting describes care of young given by individuals other than the immature's mother. Though there are risks inherent in delegating infant wellbeing to individuals with variable incentive to deliver high quality or altruistic care, effective alloparenting can alleviate some of a mother's energetic burden (Hrdy 2000).

It has long been recognized that humans show characteristics of cooperative breeders (Hrdy 2007; Kramer 2005). Childcare is often a cooperative enterprise with variable contributions from juvenile siblings, other adult females, and post-reproductive females. Pair-bond formation usually involves contributions from males toward provisioning mates and offspring and providing protection from other males. The fitness benefits of these activities are usually described as the enhanced survival of offspring (Washburn and Lancaster 1968, Lovejoy 1981, Hawkes et al, 1998, Marlowe 1999a, Lahnedperaä et al 2004), though recent analyses indicate that male provisioning contributes more to birth rate than to offspring survival (Apicella and others 2007; Marlowe 2003). Literature on primates and social carnivores recognizes the contributions of both juveniles and mature individuals to the care of infants (Solomon and French 1997). Traditionally, cooperative breeding paradigms in humans have been constrained to a one-way flow of resources between generations, in which adults cooperate to subsidize young and juvenile contributions ultimately subsidize themselves (Draper and Harpending 1987; Kramer 2002; Kramer 2005; Lee and Kramer 2002; Weisner 1987). This top-down energy flow model depicts community members as either producers/providers or sometimes self-subsidizing consumers.

\section{Synthesis: Final Common Pathway, Indirect and Direct Reproductive Effort, and the Pooled Energy Budget}

By uniting the physiological insights of reproductive ecology with the social framework of cooperative breeding, it is possible to trace the transfer of energy both within and between bodies in human breeding communities. Taking into account an ancestral ability to facultatively shift energy within bodies, the propensity to share energy across individuals, and the ability to alleviate the activity costs of others, we introduce three concepts that can help us describe human life history:

1. Final Common Pathway: The mother's physiology, as in all primates, is the ratelimiting step for reproduction. Energy impacts reproduction insofar as it flows through the mother, the only individual who can gestate and suckle young, making her the final common pathway for metabolic investment in reproduction.

2. Direct versus Indirect Reproductive Effort: Energy that an individual invests in his or her own offspring we term direct reproductive effort. Direct reproductive effort includes mating effort, both behavioral and somatic (such as skeletal muscle growth in males), and 
parenting effort, via gestation and lactation in females and infant care in mothers and fathers. As discussed above, only reproductive-aged females can gestate and nurse young. This type of direct reproductive effort must be minimally sufficient; other types of direct reproductive effort can be accomplished in variable increments.

Energy invested in the production of offspring other than one's own constitutes indirect reproductive effort. An important characteristic of indirect reproductive effort is that it need not be minimally sufficient. An individual incapable of direct reproductive effort, or unable to generate minimally sufficient direct reproductive effort, can still contribute indirect reproductive effort. However, to qualify as indirect reproductive effort in the sense we intend, energy must eventually flow through the final common pathway. Behavior that contributes to survival probabilities only does not qualify as indirect reproductive effort. Any member of the community, regardless of age, sex, or reproductive status, can contribute indirect reproductive effort. We propose that widespread contribution of indirect reproductive effort has become a characteristic feature of human life histories and has implications for childhood growth, pubertal maturation, peak reproductive performance, and reproductive senescence. Indirect reproductive effort can be considered an independent category of net energy allocation relative to growth and direct reproductive effort.

3. Pooled Energy Budget: Individuals contribute indirect reproductive effort and get their energetic needs met via the pooled energy budget. The pooled energy budget consists of the combined energetic allocations of all members of a reproductive community that might result in direct or indirect reproductive effort. These transactions can take many forms at one time and vary across the life course, discussed below. Individuals draw on the pooled energy budget by consuming calories and by diverting time and energy from reproduction. They contribute by diminishing their own energetic costs and by contributing to the energy budgets of others. The output of the pooled energy budget is the production of new individuals. Key features of the pooled energy budget include (a) the additional buffering it provides to all individuals, particularly to energy flows through the final common pathway, allowing mature female reproductive effort to be sustained at higher average levels than would be attainable by an energetically isolated individual; and (b) the possibility of trade-offs in energy allocations that are inter-somatic as well as intra-somatic via the leveraging of time, energy, and skill across age, sex, and reproductive classes.

\section{Contributors to the pooled energy budget}

Integrating the energetic focus of reproductive ecology with a behavioral ecological perspective even broader than that of cooperative breeding suggests that the structure of human society itself is integral to the slow childhood growth, late age at maturity, overlapping dependent offspring, and age-dependent declines in female reproductive effort that characterize human life history. The indirect reproductive effort contributions of pre-reproductive, reproductive, and post-reproductive individuals, both male and female, are all important, and without these it would be impossible to funnel as much energy through the final common pathway as human societies characteristically do. 
Particularly for females, direct reproductive effort requires a minimally sufficient investment of energy: producing part of a baby is not feasible.

It is important to recognize that an individual can contribute indirect reproductive effort to the pooled energy budget without being a net producer. Pre-reproductives are a key group in the latter category. Work with Maya subsistence agriculturalists indicates that humans begin to produce more calories than they consume in their mid to late teen years, correlating with age at marriage and the subsequent start of child rearing. The data also reveal, however, that there is a long slope between being a complete consumer and producing enough to satisfy one's own needs; during childhood, juveniles become increasingly competent at a variety of subsistence tasks (Kramer 2002; Kramer 2005; Lee and Kramer 2002). These results have been interpreted as indicating that children underwrite increasing portions of their own nutritional costs. We take the interpretation a step further and suggest that pre-pubertal children, by procuring some of their own food, contributing raw materials to the common budget, and participating in self-care and in care of other children, have the net effect of lessening the energetic burden on the final common pathway. While this claim is not entirely novel (see Gurven and Walker 2006), we emphasize the integration of juveniles into a species-wide life behavioral and life history profile. We note that the presence of children does not increase maternal fertility rates relative to no or fewer children, but that children who contribute energy increase maternal fertility relative to the same number of children who do not.

Among the contributions of reproductive-aged individuals, those of fathers have received substantial attention. Male provisioning, particularly through hunting, has had considerable positive impact on the baseline of energy available within the community (Lovejoy 1981; Marlowe 1999a; Marlowe 1999b; Marlowe 2000; Washburn and Lancaster 1968). Other reproductive-aged individuals contribute to the pooled energy budget through shared childcare (Ivey 2000).

Inputs of post-reproductives have recently been highlighted (Hawkes and others 1998; Sear and others 2000). These individuals, both male and female, are net producers with a mature subsistence skill set and without opportunities for direct reproductive effort. A schematic summarizing contributions to the pooled energy budget by reproductive status is presented in Fig 1.

(Fig. 1. here)

Over the course of a lifetime, we can conclude, an individual's contributions to the pooled energy budget change in degree and character. Consider the life course of a female human (Fig 2A). In infancy, energy is partitioned between growth and maintenance. Beginning in late infancy or early childhood, a small portion of energy can be allocated to indirect reproductive effort. This might mean that the child is able to walk rather than being carried, or that she can feed herself simple foods. It might also mean that she is able to collect and share some of those simple foods. The trend continues in the juvenile period, when capacities extend to more complicated or labor intensive subsistence, self-care, and childcare tasks. In so doing, the juvenile liberates the time and energy of group members with higher reproductive and caloric returns on their time. Note 
that, in these life history phases, the juvenile's energy allocation to growth is reduced (Bogin 1999a). It increases again at puberty, while investment in indirect reproductive effort may decline, as evidenced by decreased activity in energetically stressed individuals (Benefice and Cames 1999; Benefice and others 2001a; Benefice and others 2001b; Garnier and Benefice 2001). Growth decreases sharply in late adolescence. This is expected from life history theories in which growth and reproduction represent alternative categories for the allocation of "surplus" energy: late adolescence represents the first opportunity to invest in direct reproductive effort. Early and middle adulthood are a female's prime childbearing years; during this time, indirect reproductive effort is predicted to be low. With increasing age in adulthood, direct reproductive effort begins to decline while investment in maintenance and indirect reproductive effort increases. In the post-reproductive period, as in the juvenile period, only indirect reproductive effort is possible.

The notable feature of this model is the fact that there are three alternative categories for net energy, not just two: growth, indirect reproductive effort, and direct reproductive effort. Many of the paradoxes noted above can be resolved through the recognition of indirect reproductive effort as an independent energy allocation category.

Compare the schematic of energy allocation in humans to that of a chimpanzeelike last common ancestor of humans and chimpanzees (Fig 2B). Juveniles of this phylogenetic node might supplement maternal nursing with simple foraging, but they do not reduce the amount of energy invested in growth, and they do not obtain food for others. Females of the last common ancestor, like females of modern chimpanzees, likely made the classical, direct transition from growth and maintenance to reproduction and maintenance. They had neither the slow juvenile growth nor the extended postreproductive lifespan of modern humans, and they did not contribute significant indirect reproductive effort. Once committed to direct reproductive effort, they likely increased allocation to this category with age, perhaps retaining sufficient allocation to maintenance to survive the dependency period of their last offspring.

(Fig. 2. here)

\section{Life history consequences of indirect reproductive effort}

Indirect reproductive effort may be a selective force on both pre- and postreproductive life spans. First, the capacity to allocate energy to indirect reproductive effort may result in slower childhood growth; some of the energy that would be allocated to growth, in a last common ancestor, is devoted to indirect reproductive effort in juvenile, pre-pubertal humans. This contrasts with views which attribute slowed childhood growth to the need for learning and brain development (Aiello and Wheeler 1995; Hill and Kaplan 1999). The widely recognized sensitivity of growth rate to energy availability does not accord well with models of slow juvenile growth in the service of knowledge and experience acquisition (Eveleth and Tanner 1976). If such things were fundamentally limiting, one would expect human growth rates to be much less plastic.

We do not mean to suggest that allocation of energy to indirect reproductive effort, especially among pre-reproductives, is voluntary: as in other cooperative breeding 
species, we envision a "pay to stay" model, in which pre-reproductive indirect reproductive effort is more or less compulsory (Kokko and others 2002). Opportunities to allocate energy to indirect reproductive effort may vary with subsistence ecology, however. For example, paleoathropological evidence indicates a decline in both overall health and juvenile growth rates during the Neolithic transition from foraging to agriculture (Larsen 1995). Increased disease load and decreased nutrition doubtless contributed to these trends. It is possible that, in addition, increased energy expenditure in children with the advent of agriculture contributed to declining growth rates. Studies in current transitional societies are needed to test this hypothesis. In any case, a moderate retardation of growth rate in childhood relative to infancy and to adolescence has become an obligate feature of life history in humans; even abundantly well-nourished juveniles show a version of this growth pattern (Bogin 1999a).

Childhood investment in indirect reproductive effort may lead to slower growth but not to different size at maturity, necessitating the postponement of maturation. Evidence from females in nutritionally stressed populations indicates that energy expenditure, particularly in small girls, is lower at adolescence than in larger girls, and that energy expenditure in all females decreases from adolescence to reproductive maturity (Benefice and others 2001a; Benefice and others 2001b; Garnier and others 2005; Thomas and others 2001). These observations support the view that energy is limiting during adolescence, as well as in reproduction, and that reductions in expenditure during the growth period can be part of a successful strategy. By the same logic, we must recognize contributions of effort to the pooled energy budget by pre-reproductives as costly. They could allocate more energy to their own growth if they reduced their physical activities.

As noted earlier, human females have shorter interbirth intervals than expected, especially given the cost of an individual offspring and the protracted length of dependency of young. Models of cooperative breeding that envision the efforts of other group members as alleviating the energetic burdens faced by a mother cannot account for the fact that her rate of reproduction is actually higher than expected for a hominoid her size. It is not enough to reduce her need to allocate metabolic energy to non-reproductive tasks. We must account for her funneling more energy through her final common pathway than metabolic scaling can account for (see Bogin, this issue). This is possible because of her ability to absorb and store energy over and above her metabolic capacity and then to allocate it to the final common pathway.

The rate of reproduction of human females is not as high in either the early reproductive years or in the late reproductive years as it is during the peak reproductive years (Apter and others 1978; te Velde and Pearson 2002; Vihko and Apter 1984). Increasing reproductive effort with age in early maturity is not surprising and is in fact predicted by standard life history theory and observed in many other primates. The decrease in reproductive rate in the later reproductive years is surprising, however, both theoretically and comparatively. According to classical life history theory, as individuals age, the value of investing in survivorship should decline while the benefits to investing in reproduction should increase proportionately (Gadgil and Bossert 1970; Williams 1957). In fact, however, human females begin to reduce energy allocated to direct reproductive effort relative to indirect reproductive effort well in advance of menopause. Both physiological factors (Ellison 1994; Ellison 1996) and behavioral factors (Rao and 
Demaris 1995) probably contribute. In Pan, however, recent data suggest that, in robust individuals, the likelihood of closing an open birth interval does not decline with age as it does in human females (Emery Thompson and others 2007).

Additional evidence of the shift in energy allocation away from direct reproductive effort in reproductive-age human females can be found in the divergence of survivorship and fertility trajectories after age 30. In most species, including chimpanzees (Emery Thompson and others 2007), female survivorship and fertility follow parallel trajectories of decline with age; human females, however, have fertility trajectories that decline more rapidly and survivorship trajectories that decline less rapidly in this period than expected for an ape of our size. In our view, this is because female reproductive effort in a cooperative breeding group begins to take on a mixed character with increasing age, shifting increasingly towards indirect reproductive effort via allocations to the care and survival of extant offspring and away from production of new offspring. Indirect reproductive effort does not have a minimum sufficient level and therefore allows for a tapering off of total reproductive effort in a gradual fashion, consistent with a gradual increase in maintenance effort over the same period and with increasing survivorship as menopause approaches.

An increasing likelihood of post-reproductive survival would result, reflected in the fact that human mortality rates do not show an abrupt inflection at menopause (Williams 1957). While Hawkes and others have argued that the indirect reproductive effort of post-reproductive females provides positive selective pressure for increased longevity (Alvarez 2000; Blurton Jones and others 2002; Hawkes 2003; Hawkes 2004; Hawkes and others 1998; Hill and Hurtado 1991; Mace 2000), we propose that the shift in energy allocation from direct to indirect reproductive effort before menopause promoted the existence of post-reproductive life, which in turn selected for increased indirect reproductive effort after menopause, rather than the other way around.

Allocation of energy to indirect reproductive effort is not simply or exclusively a post-reproductive strategy, however. It is a variable component of the energy allocation strategy throughout the human life history, made possible by the existence of the pooled energy budget.

\section{Conclusion}

The perspective discussed above emphasizes energy dynamics and the physiological and social interactions that permit consistent, high volume energy transfers within and between individuals. It differs from other models of human life history evolution in the following ways:

1. The pooled energy budget is a model of the energetic rationale for human life history that focuses on how inter-somatic energetic changes since the split from a last common ancestor with chimpanzees result in novel patterns of energy allocation towards reproduction, including allocation to the category of indirect reproductive effort.

2. Social transactions such as alloparenting are assessed primarily for their impact on female reproductive function rather than their impact on child survival.

3. Allocations of energy to childcare and domestic tasks by juveniles and others are viewed primarily in terms of their effect in leveraging the energy returns of those with 
greater efficiency in directly productive tasks, and hence in terms of their impact on the flow of energy through the final common pathway.

4. The pooled energy budget model interprets slow childhood growth in humans as a result of a diversion of energy allocation toward indirect reproductive effort. This diversion is dramatically reduced at adolescence, resulting in a marked acceleration of growth immediately prior to the initiation of direct reproductive effort. Other models portray slow childhood growth as both the result of relaxation of a constraint and a desirable outcome in itself, "permitted" by low juvenile mortality resulting from group living and alloparenting. No explanation is given in these models for why human juveniles would not respond to lower mortality, and hence lower maintenance costs, with faster, rather than slower, growth. Nor is any explanation offered for the "missing" surplus energy that slow juvenile growth generates.

5. Similarly, the pooled energy budget model interprets declining female fecundity with increasing age in advance of menopause as a reflection of declining allocations of energy to direct reproductive effort and increasing allocations to indirect reproductive effort and maintenance. Other models suggest that post-reproductive individuals, by investing in kin, may generate positive selection pressure against mortality in the post-reproductive period. They do not, however, explain why allocation of energy to direct reproductive effort should decline in advance of menopause, a shift that must have preceded selection of post-reproductive mortality in order for there to be adaptively significant survivorship at menopause.

Uniting the pooled energy budget with our understanding of how bodies store, mobilize, and allocate energy lets us examine how humans "smooth out" inequalities in productive ability over the lifespan. From an energetic standpoint, the work of life growing, reproducing, and maintaining the organism - requires calories, but, as discussed above, energy requirements are not the same at all junctures. Some of life's tasks, including gestation, lactation, and adolescent growth, are more energy-intensive than others. An individual's ability to generate calories, furthermore, isn't always commensurate with her requirements. By including multi-directional, inter-somatic energetic transfers as a characteristic trait of human communities, the pooled energy budget proposes a mechanism for smoothing out the disjuncture between productive capabilities and consumption needs over the life course.

In addition to smoothing out the bumps in productive ability over the course of the lifespan, the pooled energy budget acts to increase the minimum amount of energy available within the group at all times. The human ability to generate and distribute surplus energy surpasses that of chimpanzees. This is important in sustaining expensive tissue and in accelerating reproductive rate. 


\section{Literature Cited}

Aiello LC, Wheeler P. 1995. The expensive-tissue hypothesis: the brain and the digestive system in human and primate evolution. Curr Anthropol 36(2):199-221.

Alvarez HP. 2000. Grandmother hypothesis and primate life histories. Am J Phys Anthropol 113(3):435-50.

Apicella CL, Feinberg DR, Marlowe FW. 2007. Voice pitch predicts reproductive success in male hunter-gatherers. Biol Lett 3(6):682-4.

Apter D, Viinikka L, Vihko R. 1978. Hormonal pattern of adolescent menstrual cycles. J Clin Endocrinol Metab 47(5):944-54.

Benefice E, Cames C. 1999. Physical activity patterns of rural Senegalese adolescent girls during the dry and rainy seasons measured by movement registration and direct observation methods. Eur J Clin Nutr 53(8):636-43.

Benefice E, Garnier D, Ndiaye G. 2001a. Assessment of physical activity among rural Senegalese adolescent girls: influence of age, sexual maturation, and body composition. J Adolesc Health 28(4):319-27.

Benefice E, Garnier D, Ndiaye G. 2001b. High levels of habitual physical activity in west African adolescent girls and relationship to maturation, growth, and nutritional status: results from a 3-year prospective study. Am J Hum Biol 13(6):808-20.

Blurton Jones NG, Hawkes K, O'Connell JF. 2002. Antiquity of postreproductive life: are there modern impacts on hunter-gatherer postreproductive life spans? Am J Hum Biol 14(2):184-205.

Bogin B. 1999a. Evolutionary perspective on human growth. Annu Rev Anthropol 28:109-53.

Bogin B. 1999b. Patterns of Human Growth. Cambridge, U.K.; New York: Cambridge University Press.

Bribiescas RG. 2001. Reproductive ecology and life history of the human male. Am J Phys Anthropol Suppl 33:148-76.

Del Prado M, Villapando S, Lance A, Alfonso E, Demmelmair H, Kloletzko B. 2000. Contribution of dietary and newly formed arachidonic acid to milk secretion in women in low fat diets. Adv Exp Med Biol 478:407-408.

deMenocal PB. 2004. African climate change and faunal evolution during the PliocenePleistocene. Earth and Planetary Science Letters 220(1-2):3-24.

Demmelmair H, Baumheuer M, Koletzko B, Dokoupil K, Kratl G. 1998. Metabolism of U13C-labeled linoleic acid in lactating women. J Lipid Res 39(7):1389-96.

Draper P, Harpending H. 1987. Parental investment and the child's environment. In: Lancaster J, Sherrod L, editors. Parenting Across the Lifespan: biosocial dimensions. New York: Aldine de Gruyter.

Dufour DL, Sauther ML. 2002. Comparative and evolutionary dimensions of the energetics of human pregnancy and lactation. Am J Hum Biol 14(5):584-602.

Ellison PT. 1994. Advances in human reproductive ecology. Annu Rev Anthropol 23:255-75.

Ellison PT. 1995. Breastfeeding, fertility, and maternal condition. In: Dettwyler KA, Stuart-Macadam P, editors. Breastfeeding: Biocultural Perspectives. Hawthorne, NY: Aldine de Gruyter. p 305-345. 
Ellison PT. 1996. Age and developmental effects on adult ovarian function. In: Rosetta L, Mascie-Taylor NCG, editors. Variability in Human Fertility: A Biological Anthropological Approach. Cambridge: Cambridge University Press. p 69-90.

Ellison PT. 2003. Energetics and reproductive effort. Am J Hum Biol 15(3):342-51.

Ellison PT, Valeggia CR. 2003. C-peptide levels and the duration of lactational amenorrhea. Fertil Steril 80(5):1279-80.

Emery Thompson M. 2005. Reproductive endocrinology of wild female chimpanzees (Pan troglodytes schweinfurthii): methodological considerations and the role of hormones in sex and conception. Am J Primatol 67(1):137-58.

Emery Thompson M, Jones JH, Pusey AE, Brewer-Marsden S, Goodall J, Marsden D, Matsuzawa T, Nishida T, Reynolds V, Sugiyama Y and others. 2007. Aging and fertility patterns in wild chimpanzees provide insights into the evolution of menopause. Curr Biol 17(24):2150-6.

Eveleth PB, Tanner JM. 1976. Worldwide Variation in Human Growth. Cambridge New York: Cambridge University Press.

Fidler N, Sauerwald T, Pohl A, Demmelmair H, Koletzko B. 2000. Docosahexaenoic acid transfer into human milk after dietary supplementation: a randomized clinical trial. J Lipid Res 41(9):1376-83.

Fredriks AM, van Buuren S, Fekkes M, Verloove-Vanhorick SP, Wit JM. 2005. Are age references for waist circumference, hip circumference and waist-hip ratio in Dutch children useful in clinical practice? Eur J Pediatr 164(4):216-22.

Freinkel N. 1980. Banting Lecture 1980. Of pregnancy and progeny. Diabetes 29(12):1023-1035.

Gadgil M, Bossert WH. 1970. Life historical consequences of natural selection. The American Naturalist 104.

Garnier D, Benefice E. 2001. Habitual physical activity of Senegalese adolescent girls under different working conditions, as assessed by a questionnaire and movement registration. Ann Hum Biol 28(1):79-97.

Garnier D, Simondon KB, Benefice E. 2005. Longitudinal estimates of puberty timing in Senegalese adolescent girls. Am J Hum Biol 17(6):718-30.

Gurven M, Walker R. 2006. Energetic demand of multiple dependents and the evolution of slow human growth. Proc Biol Sci 273(1588):835-41.

Hachey DL, Thomas MR, Emken EA, Garza C, Brown-Booth L, Adlof RO, Klein PD. 1987. Human lactation: maternal transfer of dietary triglycerides labeled with stable isotopes. J Lipid Res 28(10):1185-92.

Hammer LD, Wilson DM, Litt IF, Killen JD, Hayward C, Miner B, Vosti C, Taylor CB. 1991. Impact of pubertal development on body fat distribution among white, Hispanic, and Asian female adolescents. J Pediatr 118(6):975-80.

Hawkes K. 2003. Grandmothers and the evolution of human longevity. Am J Hum Biol 15(3):380-400.

Hawkes K. 2004. Human longevity: the grandmother effect. Nature 428(6979):128-9.

Hawkes K, O'Connell J F, Blurton Jones NG, Alvarez H, Charnov EL. 1998. Grandmothering, menopause, and the evolution of human life histories. Proc Natl Acad Sci U S A 95:1336-1339.

Herrera E. 2002. Lipid metabolism in pregnancy and its consequences in the fetus and newborn. Endocrine 19(1):43-55. 
Hill K, Hurtado AM. 1991. The evolution of premature reproductive senescence and menopause in human females. Human Nature 2(4):313-350.

Hill K, Kaplan H. 1999. Life history traits in humans: theory and empiricial studies. Annu Rev Anthropol 28:397-430.

Homko CJ, Sivan E, Reece EA, Boden G. 1999. Fuel metabolism during pregnancy. Semin Reprod Endocrinol 17(2):119-125.

Howie PW, McNeilly AS. 1982. Effect of breast-feeding patterns on human birth intervals. Journal of Reproduction and Fertility 65:545-557.

Hrdy SB. 2000. Mother Nature: Maternal Instincts and How They Shape the Human Species. New York: Ballantine Books.

Hrdy SB. 2007. Evolutionary context of human development: The cooperative breeding model. Family Relationships 31:29-69.

Isaac G. 1978. The food-sharing behavior of protohuman hominids. Sci Am 238(4):90108.

Ivey PK. 2000. Cooperative reproduction in Ituri Forest hunter-gatherers: Who cares for Efe infants? Curr Anthropol 41(5):856.

Janson C, van Schaik C. 1993. Ecological risk aversion in juvenile primates: slow and steady wins the race. In: Pereira M, Fairbanks L, editors. Juvenile Primates: Life History, Development, and Behavior. New York: Oxford University Press. p 5774.

Jasienska G, Thune I, Ellison PT. 2006. Fatness at birth predicts adult susceptibility to ovarian suppression: an empirical test of the Predictive Adaptive Response hypothesis. Proc Natl Acad Sci U S A 103(34):12759-62.

Kaplan H, Gurven M. 2005. The natural history of human food sharing and cooperation: a review and a new multi-individual approach to the negotiation of norms. In: Gintis H, Bowles S, Boyd RT, Fehr E, editors. Moral Sentiments and Material Interests: The Foundation of Cooperation: MIT Press. p 75-113.

Kaplan H, Hill K. 1985. Food sharing among Ache foragers: tests of explanatory hypotheses. Curr Anthropol 26(2):223.

Kaplan H, Hill K, Lancaster J, Hurtado AM. 2000. A theory of human life history evolution: diet, intelligence, and longevity. Evolutionary Anthropology 9(4):156185.

Knott CD. 2001. Female reproductive ecology of the apes. In: Ellison PT, editor. Reproductive Ecology and Human Evolution. New York: Aldine de Gruyter. p 429-464.

Kokko H, Johnstone RA, Wright J. 2002. The evolution of parental and alloparental effort in cooperatively breeding groups: when should helpers pay to stay? Behav Ecol 13(3):291-300.

Kramer K. 2002. A case study in variability in juvenile dependence: The benefits of Maya children's work to parents. Human Nature 13(2):299-325.

Kramer K. 2005. Children's help and the pace of reproduction: Cooperative breeding in humans. Evolutionary Anthropology 14(6):224-237.

Kuzawa CW. 1998. Adipose tissue in human infancy and childhood: an evolutionary perspective. Am J Phys Anthropol Suppl 27:177-209. 
Lancaster J, Lancaster C. 1983. Parental investment: the hominid adaptation. In: Ortner DJ, editor. How Humans Adapt: a biocultural odyssey. Washington, D.C.: Smithsonian Institution Press.

Larsen CS. 1995. Biological changes in human populations with agriculture. Annu Rev Anthropol 24:185-213.

Lassek WD, Gaulin SJ. 2006. Changes in body fat distribution in relation to parity in American women: a covert form of maternal depletion. Am J Phys Anthropol 131(2):295-302.

Lee RD, Kramer KL. 2002. Children's economic roles in the Maya family life cycle: Cain, Caldwell, and Chayanov revisited. Population and Development Review 28(3):475-499.

Leonard WR, Robertson ML, Snodgrass JJ, Kuzawa CW. 2003. Metabolic correlates of hominid brain evolution. Comp Biochem Physiol A Mol Integr Physiol 136(1):515.

Lipson SF, Ellison PT. 1996. Comparison of salivary steroid profiles in naturally occurring conception and non-conception cycles. Hum Reprod 11(10):2090-6.

Lovejoy O. 1981. The origin of man. Science 211:341-350.

Mace R. 2000. Evolutionary ecology of human life history. Anim Behav 59(1):1-10.

Marlowe F. 1999a. Showoffs or providers? The parenting effort of Hadza man. Evolution and Human Behavior 20(6):391-404.

Marlowe F. 1999b. The patriarch hypothesis. Human Nature 11(1):27-42.

Marlowe F. 2000. Paternal investment and the human mating system. Behav Processes 51(1-3):45-61.

Marlowe FW. 2003. A critical period for provisioning by Hadza men: implications for pair bonding. Evolution and Human Behavior 24(3):217-229.

McCormick MC. 1985. The contribution of low birth weight to infant mortality and childhood morbidity. N Engl J Med 312(2):82-90.

McNeilly AS. 2001a. Maternal reproductive and lactational physiology in relation to the duration of exclusive breastfeeding. In: Naylor AJ, Morrow A, editors.

Developmental readiness of normal full term infants to progress from exclusive breastfeeding to the introduction of complementary foods: reviews of the relevant literature concerning infant immunologic, gastrointestinal, oral motor and maternal reproductive and lactational development. Washington, D.C.: Wellstart International

LINKAGES Project

Academy for Educational Development. p 27-34.

McNeilly AS. 2001b. Neurocrine changes and fertility in breast-feeding women. Progress in Brain Research 133.

Poppitt SD, Prentice AM, Jequier E, Schutz Y, Whitehead RG. 1993. Evidence of energy sparing in Gambian women during pregnancy: a longitudinal study using wholebody calorimetry. Am J Clin Nutr 57(3):353-64.

Prentice AM, Ceesay SM, Whitehead RG. 1993. Maternal supplementation and birthweight. Lancet 341(8836):52-3.

Prentice AM, Goldberg GR. 2000. Energy adaptations in human pregnancy: limits and long-term consequences. Am J Clin Nutr 71(5 Suppl):1226S-32S. 
Prentice AM, Goldberg GR, Poppitt SD. 1996. Reproductive stresses in undernourished and well-nourished women. Bibl Nutr Dieta(53):1-10.

Prentice AM, Poppitt SD, Goldberg GR, Prentice A. 1995. Adaptive strategies regulating energy balance in human pregnancy. Hum Reprod Update 1(2):149-61.

Rao KV, Demaris A. 1995. Coital frequency among married and cohabiting couples in the United States. J Biosoc Sci. 27(2):135-50.

Rodseth L, Wrangham RW, Harrigan AM, Smuts BB, Dare R, Fox R, King BJ, Lee PC, Foley RA, Muller JC and others. 1991. The human community as a primate society. Curr Anthropol 32(3):221-254.

Sear R, Mace R, McGregor IA. 2000. Maternal grandmothers improve nutritional status and survival of children in rural Gambia. Proc Biol Sci 267(1453):1641-7.

Skinner JD, Carruth BR, Houck K, Moran J, 3rd, Coletta F, Cotter R, Ott D, McLeod M. 1997. Transitions in infant feeding during the first year of life. J Am Coll Nutr 16(3):209-15.

Solomon NG, French JA, editors. 1997. Cooperative Breeding in Mammals. Cambridge: Cambridge University Press.

te Velde ER, Pearson PL. 2002. The variability of female reproductive ageing. Hum Reprod Update 8(2):141-54.

Thomas F, Renaud F, Benefice E, de Meeus T, Guegan JF. 2001. International variability of ages at menarche and menopause: patterns and main determinants. Hum Biol 73(2):271-90.

Valeggia C, Ellison PT. 2004. Lactational amenorrhoea in well-nourished Toba women of Formosa, Argentina. J Biosoc Sci 36(5):573-95.

Venners SA, Liu X, Perry MJ, Korrick SA, Li Z, Yang F, Yang J, Lasley BL, Xu X, Wang X. 2006. Urinary estrogen and progesterone metabolite concentrations in menstrual cycles of fertile women with non-conception, early pregnancy loss or clinical pregnancy. Hum Reprod 21(9):2272-80.

Verloove-Vanhorick SP, Verwey RA, Brand R, Gravenhorst JB, Keirse MJ, Ruys JH. 1986. Neonatal mortality risk in relation to gestational age and birthweight. Results of a national survey of preterm and very-low-birthweight infants in the Netherlands. Lancet 1(8472):55-7.

Vihko R, Apter D. 1984. Endocrine characteristics of adolescent menstrual cycles: impact of early menarche. J Steroid Biochem 20(1):231-6.

Washburn SL, Lancaster J. 1968. The evolution of hunting. In: Lee RB, Devore I, editors. Man the Hunter. Chicago: Aldine. p 293-303.

Weisner TS. 1987. Socialization for parenthood in sibling caretaking societies. In: Lancaster J, Sherrod L, editors. Parenting across the lifespan: biosocial dimensions. New York: Aldine de Gruyter.

Wich SA, Geurts ML, Mitra Setia T, Utami-Atmoko SS. 2006. Influence of fruit availability on Sumatran orangutan sociality and reproduction. In: Hohmann G, Robbins MM, Boesch C, editors. Feeding Ecology in Apes and Other Primates: Ecological, Physical, and Behavioral Aspects. Cambridge; New York: Cambridge University Press.

Williams G. 1957. Pleiotropy, natural selection, and the evolution of senescence. Evolution 11(4):398-411. 
Wrangham RW, Jones JH, Laden G, Pilbeam D, Conklin-Brittain N. 1999. The Raw and the Stolen. Cooking and the Ecology of Human Origins. Curr Anthropol 40(5):567-594. 